\title{
Dietary fibre and intestinal microflora: effects on intestinal morphometry and crypt branching
}

\author{
J S McCullough, B Ratcliffe, N Mandir, K E Carr, R A Goodlad
}

\begin{abstract}
Background-Fermentable dietary fibre has many effects on the gastrointestinal tract. One is to alter epithelial crypt cell proliferation, especially in the colon. A discrepancy between epithelial cell production rates and intestinal weights has been noted previously: crypt cell production rates only increase if bacterial fermentation occurs, but intestinal wet weight can increase in the same animals without bacterial fermentation of fibre.

Aims-To quantify intestinal cell populations in order to resolve the above paradox. Methods-Conventional and germ-free rats were fed fibre-free or fibre supplemented diets and their intestines were quantified by morphometry.

Results-There was evidence of fibre associated muscle hypertrophy in the colon, but the main effect of fibre was an increase in the number of crypts per circumference and also the number of branched crypts in the proximal colon in both groups. There was also a large increase in the number of branched crypts in the mid colon of the germ-free rats (both fibre-free and fibre supplemented). Fibre had a direct (bacteria independent) effect on goblet cells in the small intestine and a direct effect on the goblet cells in the colon, which was attenuated by the presence of bacteria. There was a notable decline in the number of enteroendocrine cells in the small intestine of the germ-free animals.
\end{abstract}

Conclusions-Fibre has several direct and

Anatomy Department, Medical Biology Centre, Queen's University of Belfast J S McCullough

Robert Gordon

University,

Kepplestone, Aberdeen

B Ratcliffe

Imperial Cancer

Research Fund,

Histopathology Unit,

Lincoln's Inn Fields,

London

N Mandir

K E Carr

R A Goodlad

Correspondence to: Dr R A Goodlad, Imperial Cancer Research Fund, 35-43 Lincoln's Inn Fields, London WC2A 3PN, UK.

Accepted for publication 19 January 1998 or to altered intestinal workload. ${ }^{3}$ In the hind gut, low residue "elemental diets" also lead to atrophy, ${ }^{45}$ which can be reversed by the addition of dietary "fibre". ${ }^{6}$ This proliferative effect of fibre was not seen in germ-free rats, despite the fivefold increase in mucosal cell proliferation in the conventional rats. ${ }^{7}$ This indicates that it is the products of fibre fermen- tation, the short chain fatty acids, that are the trophic agents for the mucosa. However, other studies have shown that some mucosal effects, especially on the small bowel, can be direct, ${ }^{8}$ and may be linked to viscosity. ${ }^{9}$ Furthermore, fibre also appears to be able to stimulate proliferation in the gastric glands directly. ${ }^{10}$

In a steady state germ-free and conventional experiment, intestinal epithelial crypt cell production rates in the distal small intestine and colon were again dramatically increased by fibre, but only in the conventional group, confirming that it is the breakdown of fibre by the colonic microflora that is responsible for its proliferative actions on the mucosa. ${ }^{10}{ }^{11}$ However, there was some discrepancy between the proliferative data and the intestinal tissue weight data, as the gross tissue weights of all the main regions of the gastrointestinal tract were increased by fibre in both the germ-free and the conventional groups, despite the lack of mucosal crypt cell proliferation in the germ-free animals. We therefore analysed the effects of the various treatments on intestinal morphology and the proportion of branching crypts.

Crypt branching is generally considered to be the visible stage of another, poorly understood way of increasing intestinal mass, namely crypt fission. Small indentations are first observed in the base of a crypt, which then ascend longitudinally leading to the symmetrical production of two new (daughter) crypts. $^{12}$ The number of crypts in the intestine increases dramatically during development, so that many branching crypts are seen in the intestine of young animals, ${ }^{13}{ }^{14}$ and also in human neonates. ${ }^{15}$ As well as a role in development, branching is seen in various damage and repair models, ${ }^{16}{ }^{17}$ and also near ulcers, where it can be reduced by non-steroidal anti-inflammatory drugs (NSAIDs). ${ }^{18}$ Although fission ultimately depends on cell division, the link may not be direct, as there is some evidence that crypts can divide before proliferative changes occur. ${ }^{15}$ Furthermore, the two phenomena can respond differently, as branching can be reduced by epidermal growth factor while crypt cell proliferation is increased. ${ }^{19}$ The significance of this process in the adult animal is not fully understood or appreciated, but the production of new crypts by fission can provide an alternative or additional means of increasing tissue mass to altered crypt cell efflux.

\section{Methods}

The rats were the offspring of a colony of germ-free Lister Hooded or a colony of genetically similar conventional animals. Two groups of conventional and two groups of germ-free 
Small intestine

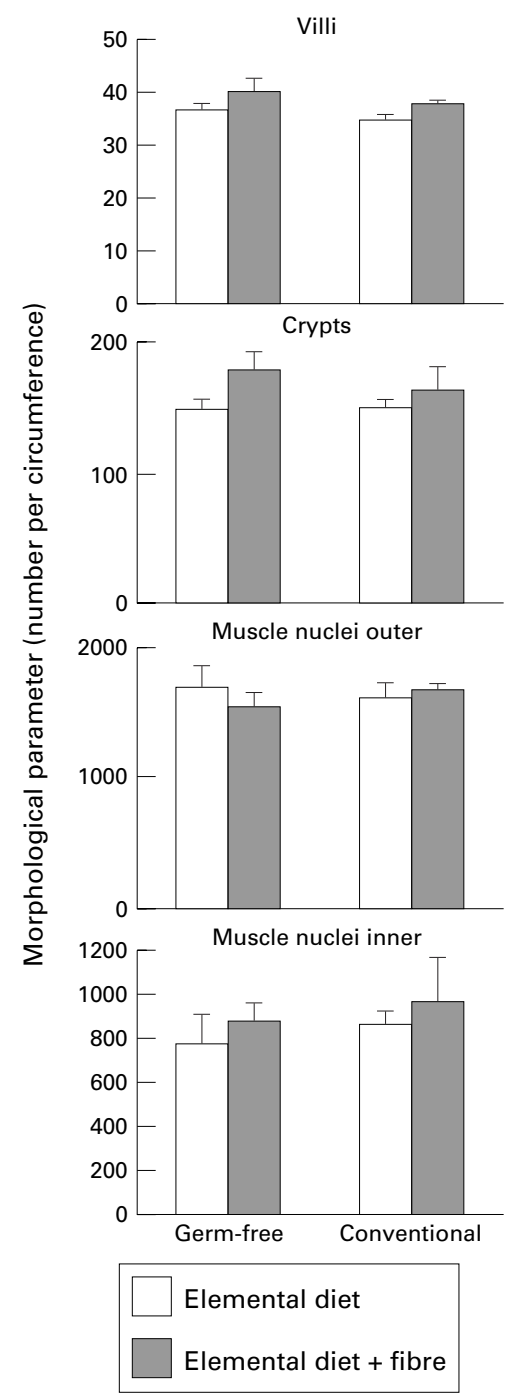

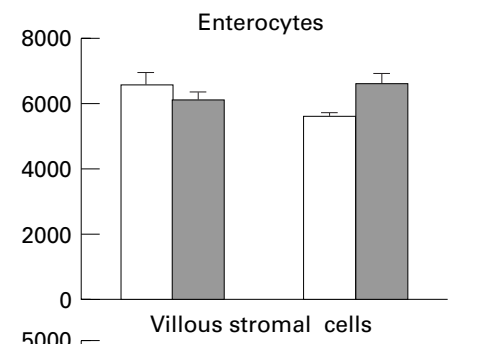
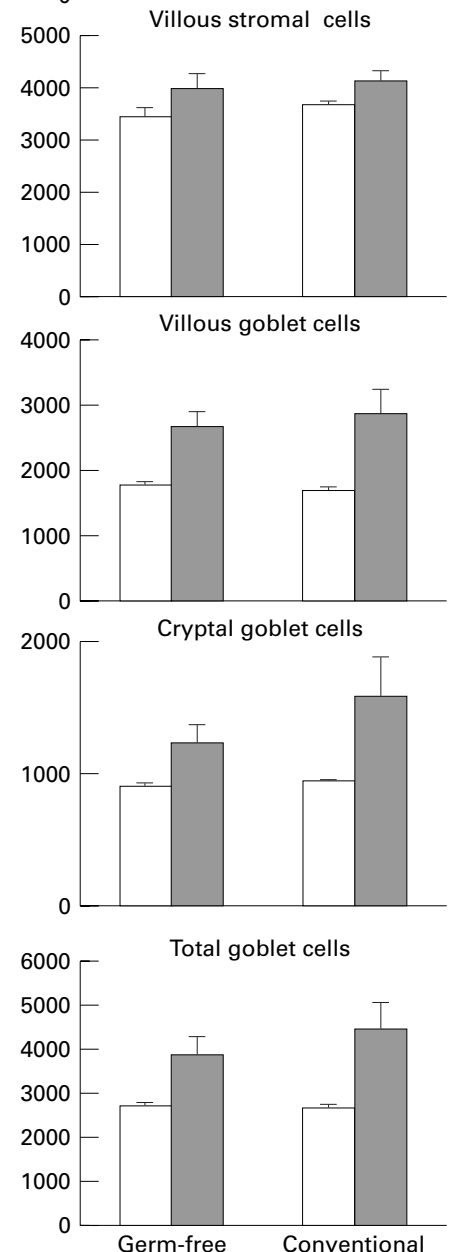
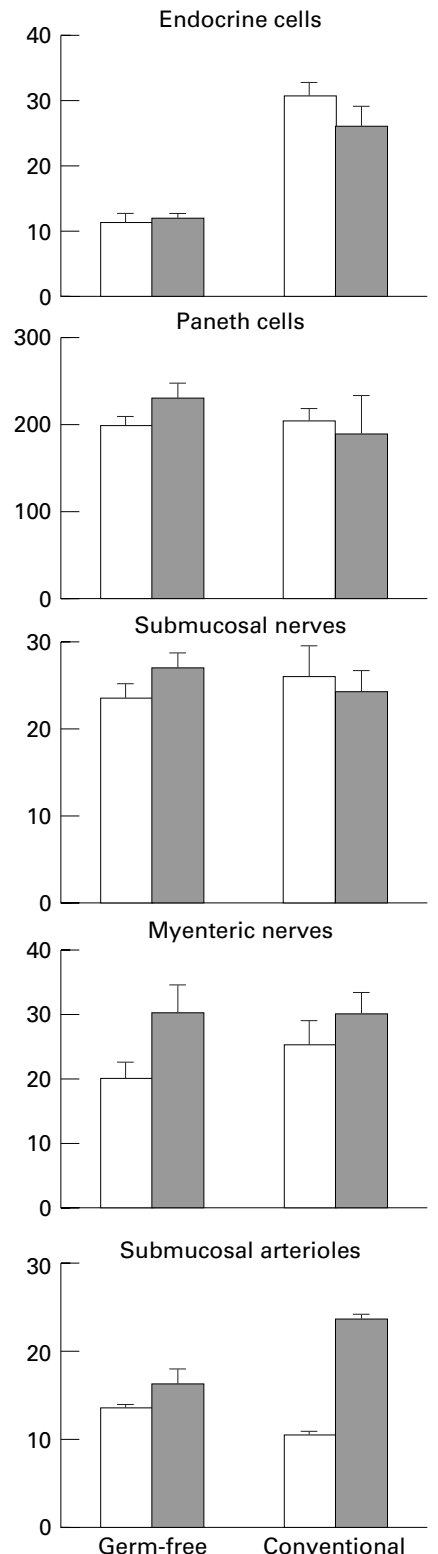

Figure 1 Effects of the fibre and flora on the morphometry of mid small intestine.

Lister Hooded rats, around $300 \mathrm{~g}$ live weight and aged 9-10 weeks, were fed a slightly restricted diet of $15 \mathrm{~g} / \mathrm{rat} /$ day of the elemental diet Flexical (Mead Johnson, Slough) or 17 $\mathrm{g} / \mathrm{rat} /$ day of a $70 \%$ Flexical, $30 \%$ fibre mixture (1:9 mixture of Ispaghula (Reckitt \& Coleman) and Trifyba (Sanofi, Wythenshawe, Manchester, UK)). ${ }^{7}$ The animals had free access to water at all times. The rats were housed in groups of 10 in stainless steel isolators. ${ }^{2021}$ Germ-free status was confirmed by methods described by Fuller. ${ }^{22}$ After two weeks the rats were weighed, injected with vincristine, and killed by ether anaesthesia and exsanguination. The intestines were removed, rinsed, blotted, weighed, and samples were fixed in Carnoy's fluid; duplicate samples were fixed in formalin.

\section{MORPHOMETRIC ANALYSIS}

One centimetre pieces of formalin fixed mid small intestine or proximal colon were taken from each of the first six rats per group for morphometric analysis. The tissue was processed for routine resin histology and sections of $2 \mu \mathrm{m}$ thickness were stained with methylene blue and basic fuchsin. Profiles of cells and structures were counted per whole circumference transverse section using the following criteria $^{23}$ for the small intestine: villi-full length profiles, continuous with the submucosa; crypts-profiles containing at least nine cells, excluding Paneth cells; enterocytes and villous stromal cells-the mean number obtained for three villi was multiplied by the number of villi per circumference; villous and cryptal goblet cells, submucosal arterioles, myenteric and submucosal nerve plexus profiles-all profiles per circumference (myenteric profiles were regarded as independent when separated by muscle); enteroendocrine and Paneth cells-all profiles within the crypts; muscle nuclei-all present for inner and outer layers of the muscularis externa. 
Table 1 Summary of effects of microflora and fibre on small intestinal parameters

\begin{tabular}{llll}
\hline Parameter & Effect of microflora & Effect of fibre & Interaction \\
\hline Enterocytes & & Increased; $\mathrm{p}<0.05$ & $\mathrm{p}<0.05$ \\
$\begin{array}{l}\text { Villous stromal cells } \\
\text { Villous goblet cells }\end{array}$ & Increased; $\mathrm{p}<0.01$ & \\
$\begin{array}{l}\text { Crypt goblet cells } \\
\text { Total goblet cells }\end{array}$ & Increased; $\mathrm{p}<0.05$ & \\
$\begin{array}{l}\text { Endocrine cells } \\
\text { Submucosal arterioles }\end{array}$ & Increased; $\mathrm{p}<0.001$ & Increased; $\mathrm{p}<0.01$ & \\
$\begin{array}{l}\text { Crypt branching } 10 \% \\
\text { Crypt branching } 90 \%\end{array}$ & Decreased; $\mathrm{p}<0.001$ & Increased; $\mathrm{p}<0.001$ & $\mathrm{p}<0.001$ \\
Length & & Increased; $\mathrm{p}<0.01$ & \\
& & Decreased; $\mathrm{p}<0.001$ & $\mathrm{p}<0.05$ \\
\end{tabular}

In the colon the following parameters per whole circumference were determined by direct examination: crypts, surface goblet cells, submucosal arterioles, muscle nuclei of the inner and outer layers of the muscularis externa, and profiles of the myenteric and submucosal nerve plexuses. The many cryptal goblet cells precluded the determination of their total numbers by direct observation and calculation. Instead, their number was estimated by counting the number of goblet cells in a randomly chosen crypt and then every tenth crypt thereafter. The mean number per crypt was then multiplied by the total number of crypts. The identification of colonocytes was made difficult by the interspersion of the numerous goblet cells. An estimate of the total number of colonocytes could not therefore be made with precision. Similarly, the number of enteroendocrine cells could not be accurately determined in the colon.

CRYPT BRANCHING INDEX

Pieces of Carnoy's fixed tissue were transferred from $70 \%$ to $50 \%$ to $25 \%$ alcohol, hydrolysed in $1 \mathrm{M} \mathrm{HCl}$ at $60^{\circ} \mathrm{C}$ for 10 minutes, and then stained in Schiff's reagent. The tissue was then carefully microdissected ${ }^{24}$ and branching and straight crypts counted (400× magnification) until a total of 200 crypts per animal had been scored. Crypt branching was defined by the appearance of a split or fissure in the base of the crypt. The crypts scored as branched ranged from small indentations (accompanied by an invagination of the basement membrane) to fissures in which the crypts were almost separated. All samples were scored blind by one observer to avoid variation between readers.

\section{STATISTICS}

All results are presented as mean (SEM). Data were tested by a two sided $t$ test, or by two way analysis of variance. The data were classified by two factors, diet and microflora. It is possible for one of these two factors to alter the effect of the other, measured by the interaction effect. In addition, branching data from three sites in the

Table 2 Summary of effects of microflora and fibre on colonic parameters

\begin{tabular}{llll}
\hline Parameter & Effect of microflora & Effect of fibre & Interaction \\
\hline Crypts & & Increased; $\mathrm{p}<0.001$ & \\
$\begin{array}{l}\text { Surface goblet cells } \\
\text { Crypt goblet cells }\end{array}$ & Decreased; $\mathrm{p}<0.001$ & & \\
Total goblet cells & Increased; $\mathrm{p}<0.05$ & Increased; $\mathrm{p}<0.001$ & \\
$\begin{array}{l}\text { Myenteric plexus } \\
\text { Muscle nuclei outer }\end{array}$ & Decreased; $\mathrm{p}<0.05$ & Increased; $\mathrm{p}<0.001$ & $\mathrm{p}<0.001$ \\
Length & Increased; $\mathrm{p}<0.05$ & Decreased; $\mathrm{p}<0.01$ & \\
$\begin{array}{l}\text { Crypt branching } 10 \% \\
\text { Crypt branching } 50 \%\end{array}$ & Decreased; $\mathrm{p}<0.001$ & Increased; $\mathrm{p}<0.001$ & \\
\hline
\end{tabular}

small bowel or colon were subjected to three way analysis of variance, with the site as the third variable.

\section{Results}

We have previously reported that the weights of all the regions of the gut were significantly heavier in the fibre supplemented groups for the germ-free and conventional animals (stomach $30 \%$ and $20 \%$, small intestine $4 \%$ and $6 \%$, caecum $17 \%$ and $27 \%$, and colon $50 \%$ and $48 \%$, respectively). ${ }^{11}$ No significant differences between groups were seen in the weights of the other major organs (liver, heart, lungs, kidneys, and spleen).

No proliferative effect of fibre or of microflora was observed in the mid small intestine but a proliferative effect of fibre was seen in the distal small intestine and proximal, mid, and distal colon, but only in the conventional groups $(43 \%, 256 \%, 196 \%$, and $97 \%$, respectively)..$^{10}$

Figure 1 and tables 1 and 2 show the effects of the various treatments on the morphometry of the mid small intestine. There appeared to be a slight increase in the number of villi and crypts per circumference but this was not statistically significant. Little effect on muscle nuclei was observed. Fibre increased the counts of villous stromal cells and of villous and cryptal goblet cells. The most dramatic effect was seen on the endocrine cells with counts being much reduced in the germ-free group. Fibre also increased the submucosal arteriole counts, with the presence of microflora enhancing this.

Figure 2 presents the results of the morphometric analysis of the proximal colon. Fibre was associated with a very highly significant increase in the number of crypt profiles per circumference. While there were more surface goblet cells in the germ-free animals, both fibre and microflora increased the goblet cell count in the glands and thus the total goblet cell count. There was a small interactive effect on the total goblet cell count. Both fibre and microflora altered the outer muscle nuclei count, with the counts being greater in the conventional groups and reduced by fibre.

Figure 3 shows the crypt branching index (CBI) data for the small intestine and colon. The effects appeared to vary according to site studied, with fibre increasing CBI in the proximal and distal regions of the small intestine, and having little effect in the mid small intestine. Bacteria only had an effect in the distal small intestine, where they reduced branching and reduced the response to fibre. Three way analysis of variance (for all sites) showed that flora, fibre, and site had significant effects $(\mathrm{p}=0.001,0.003$, and 0.001 respectively) and that very highly significant interactions $(p<0.001)$ between bacteria and site and fibre and site occurred.

Fibre significantly increased branching in the proximal colon, but had little effect in the mid and distal colon, although the values were slightly greater in all the supplemented groups. In the mid colon the lack of intestinal microflora very significantly increased the CBI. 

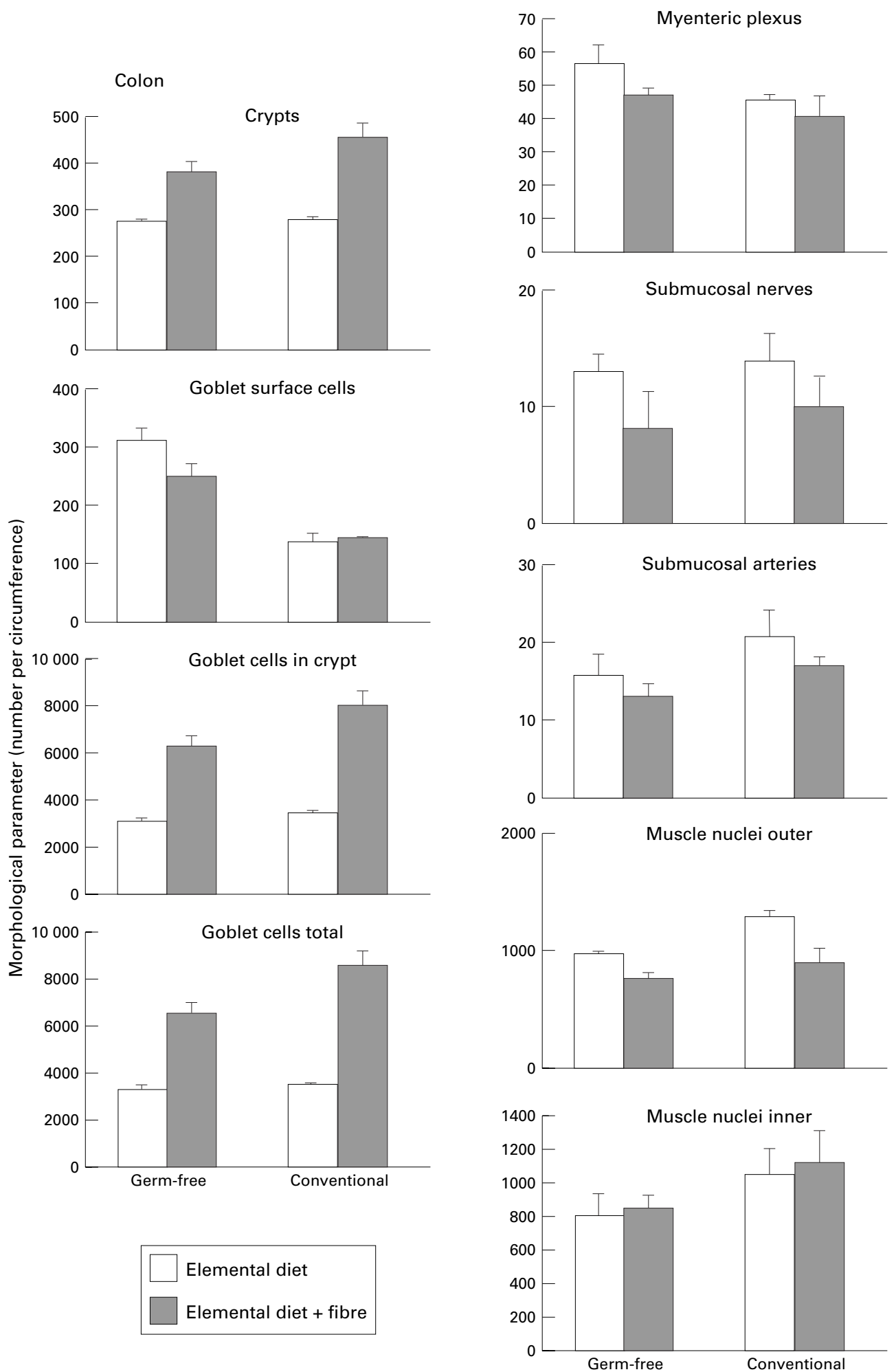

Figure 2 Effects of the various treatments on the morphometry of proximal colon.

No interactions between fibre and flora were seen. Three way analysis confirmed the significant effects of flora, fibre, and site $(p=0.001$, 0.03 , and 0.001 respectively) with the only interaction effect being between bacteria and site $(\mathrm{p}<0.001)$.

The lengths of the small intestines (fig 4) were slightly shorter in the fibre supplemented groups $(\mathrm{p}=0.053)$; however in the colon, fibre was associated with a significant increase $(\mathrm{p}<0.001)$ in length.

\section{Discussion}

Dietary fibre can be used as a very loose term to encompasses a large variety of carbohydrates, which explains why there are still considerable problems in agreeing on its definition and analysis. ${ }^{25}$ The original concept of 

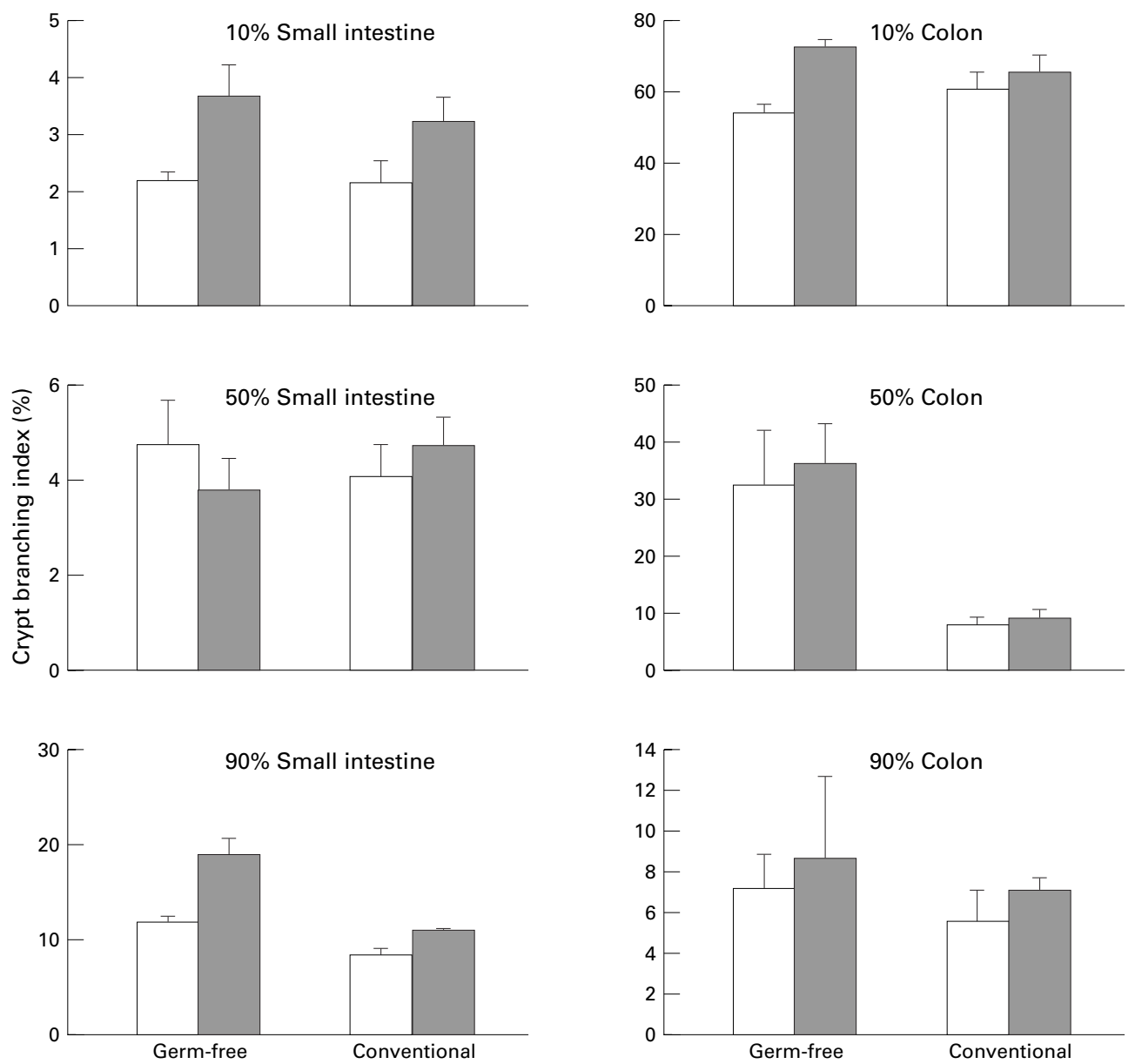

Elemental diet

Elemental diet + fibre

Figure 3 Effects of the various treatments on the crypt branching index of the small intestine and colon. Sites in the intestine were identified by relative length.

dietary fibre was as ingested plant cell wall material; however, if one considers the fate of fibre to be fermentation in the colon, the definition can be extended to cover any non-starch polysaccharide not degraded by endogenous mammalian enzymes that reaches the colon. ${ }^{27}$ Consequentially, various types of fermentable non-fibrous materials can have "fibre-like" actions; this definition thus includes large quantities of resistant $\operatorname{starch}^{28}$ and also intestinal mucins. ${ }^{29}$ The arrival of these agents has a far reaching range of actions, which include dilution or binding of carcinogens, minerals, and vitamins; alteration of bile acid and cholesterol levels; induction of xenobiotic metabolising enzymes ${ }^{30}$; delayed gastric emptying and damped glycaemic response; stool softening; altered transit times for the digesta; and increased stool output. In addition, the interaction of fibre with the bacterial flora leads to the production of short chain fatty acids (SCFAs) by microbiological fermentation, which then has many further ramifications, as the SCFAs profoundly alter the luminal environment; for example, the resulting lower luminal $\mathrm{pH}$ increases SCFA uptake and water absorption. Fibre can also alter the intestinal microflora, and stimulate production of mucus, vitamin $\mathrm{K}$ absorption, mucosal blood flow, and motor activity. ${ }^{31}$

The fibre mixture that we used was chosen to have a high degree of fermentability and also of bulk; thus it should have provided both a "substrate" for fermentation, a "matrix" for bacterial colonisation, and mechanical properties. We thus think that it should be representative of the types of fibre generally consumed; however, it should be stressed that there is a vast range of dietary fibre types, and our results may not apply to all of these. We have shown previously that this fibre mix can have major proliferative effects on the intestinal mucosa, especially of the colon. ${ }^{6}$ We used germ-free and conventional animals in an attempt to determine whether these effects were direct, or whether they were dependent on the breakdown of fibre by the intestinal microflora. Our first experiment used a starvation and refeeding model, ${ }^{7}$ but the magnitude of the response was such that in later experiments we could allow the intestine to adapt to the diets, which normally is complete within nine days. ${ }^{32}$ While the main conclusion of these further studies remained 
Elemental diet

Elemental diet + fibre

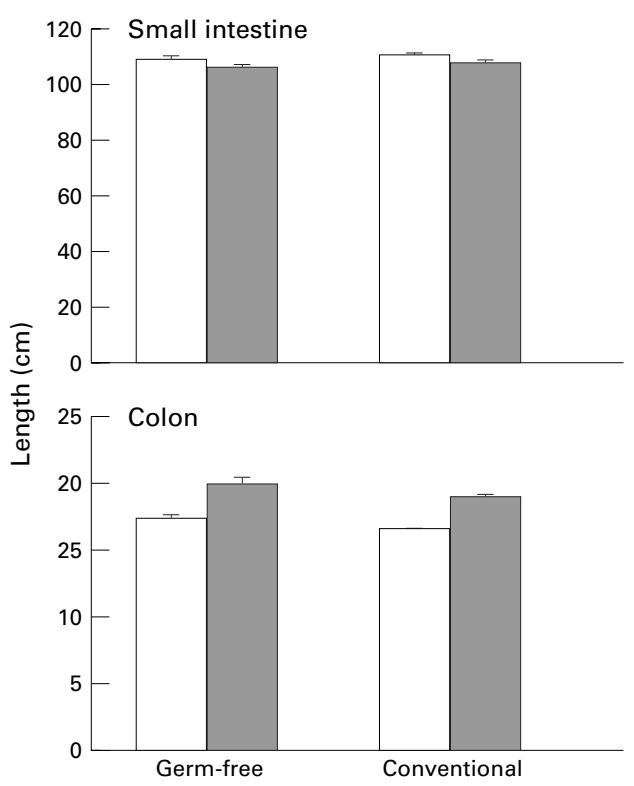

Figure 4 Effects of the various treatments on the lengths of the small bowel and colon.

the same, namely that the predominant effects of fibre were to stimulate the crypt cell proliferation of the mucosa, and that this required the presence of the microflora, ${ }^{11}$ we also found evidence of smaller viscosity related proliferative effects ${ }^{9}$ and furthermore that fibre could have direct effects on the gastric mucosa. ${ }^{10}$ In addition, we have shown that there are substantial increases in the levels of the plasma hormones enteroglucagon and peptide YY of the germ-free $\mathrm{rat}^{34}$; thus the notable depletion of endocrine cells seen in this morphological study could perhaps indicate an exhaustion of secretory granules. The response of these hormones to fibre differed, in that fibre decreased enteroglucagon and peptide YY in the germ-free rat, but increased them in the conventional rats. Gastrin and insulin were significantly lowered in the fibre supplemented groups, but not affected by the microflora.

The apparent increase in the number of submucosal arterioles was interesting, as it may indicate the dilatation of previously contracted vessels and supports the reports that SCFAs stimulate blood flow. ${ }^{35}$ The effect in the colon was not significant, while that in the small bowel was highly significant, with a small effect in the germ-free rat, and a much larger effect in the conventional rat.

Another major finding was that fibre was associated with elevated mucous cell counts in both the small and the large bowel. There are a few reports of fibre induced mucus production in vivo, ${ }^{36}{ }^{37}$ and it is of interest that this does not appear to be fermentation dependent in the small bowel; in the colon there does seem to be an effect of the microflora, which is somewhat at odds with reports of reduced mucus production when SCFAs are added in vitro. ${ }^{38}$ This serves to reinforce the point that there may well be major differences in the response of a cell in a well ordered, defensive system such as the gut in vivo and when the cell is immersed in the chemicals that it normally metabolises or transports.

The main impetus for undertaking the morphometric analyses presented here was to investigate the discrepancy between the mucosal proliferative data and the weight data. Earlier studies have indicated that fibre can stimulate both the muscle and the mucosa ${ }^{59}{ }^{40}$; thus we thought that the most likely explanation was that there were changes in the muscle layer. While there was some evidence of this, it did not seem sufficient to explain the large effects of fibre on tissue weight. Morphometry did however indicate that there was a small increase in the number of crypts and villi per circumference in the small bowel and a large increase in the number of crypts in the colon. This was generally substantiated by the data on the number of branching crypts observed in the small intestine and colon and by the increases in length of the colon. However not all sites studied appeared to bear this out, and there was an additional factor in that very large indexes were seen in the mid colon of the germ-free rat. Crypt branching is the visible stage of a process that can go on to make new crypts (crypt fission), but our knowledge of the time course and probability of branching progressing to fission is incomplete. To date we have little information on the time course of crypt fission and few studies provide the opportunity to investigate the progression of the so called crypt cycle. One such model is to stain glucose-6-phosphate dehydrogenase producing crypts, as this activity is lost following mutation in heterozygous mice. The size of the resultant "patches" of lost enzyme activity increases with time, which shows that some of these crypts can indeed divide. ${ }^{41}$ The lack of chronic bacterial action in the germ-free colon may stop or delay the normal developmental programme. Some aspects of the germ-free colon appear "fetal", for example there is a notable expansion of the surface epithelium, which explains the expansion of the surface goblet cells. Nevertheless, the very high number of branched crypts, without evidence of massive hyperplasia, in the proximal colon of both groups and in the mid colon of the germ- free rats would imply that not all branching crypts have to go on to divide. It is for this reason that it is important to distinguish between the observed presence of branched crypts and the often implied assumption that all these crypts are in fission.

The significance of increased crypt branching and fission is still a matter for speculation, but it may be of great significance, especially if it is driven by stem cell events, as the stem cells are likely to be the "Achilles heel" of the cell renewal system in the gut. It is of some interest that there is also increased crypt branching indexes in mice with multiple intestinal neoplasia ${ }^{42}$; thus increased fission, like increased proliferation may be considered as a marker of carcinogenesis risk or a means for 
clonal expansion of initiated cells. Crypt fission may also play a role in the clonal expansion of carcinogenesis, as a solitary mutated crypt can develop into a monoclonal patch over time via crypt fission. ${ }^{41}$ Although crypt fission is ultimately dependent on cell production, it may not be directly linked, as fission may occur before cell proliferation. ${ }^{15}$

There is still considerable debate over the role of proliferation in neoplasia, with many models including hyperplasia as a promoter of initiated mutational events. It is a matter of some concern that while some experimental studies show reduced carcinogenesis with high fibre diets, an equivalent number show increased carcinogenesis, leading to the somewhat contentious suggestion that we should exercise caution in adding fermentable fibre supplements to our foods. ${ }^{43}$ If deregulation of fission also has a role in tumour initiation and neoplastic expansion, similar arguments may also apply, and our need for further information is thus very urgent.

There were large differences in branching indexes, and in the response of branching between sites in the gut; the significance of this is not yet clear, but we are in the process of establishing baseline values in a variety of models, which should help illuminate these phenomena.

In conclusion, we have shown a whole range of effects of fibre on the stomach, small intestine, and particularly on the colon. Some effects, such as those on the mucus cells and crypt branching in the small bowel are direct, while others, especially the proliferative ones on the colonic mucosa are indirect, that is they require the presence of the microflora. Other effects are more complex, in that direct and indirect effects coexist, as was shown by the crypt branching in the colon. Crypt branching is a poorly understood phenomenon, but it can provide an alternative means of increasing tissue mass. Furthermore these increases will not be detected by most conventional proliferative assays. The implications of these findings are still a matter of interpretation, but may well prove to be of considerable biological significance.

We wish to thank P Brennan for his assistance with the morphometrical analyses.

1 Goodlad RA, Plumb JA, Wright NA. The relationship between intestinal crypt cell proliferation and water absorption measured in vitro in the rat. Clin Sci 1987;72:297-304.

2 Goodlad RA, Lee CY, Wright NA. Cell proliferation in the small intestine and colon of intravenously fed rats: effects of urogastrone-

3 Goodlad RA, Wright NA. Epithelial kinetics, control and consequences of alterations in disease. In: Whitehead $\mathrm{R}$ ed. Gastrointestinal and oesophageal pathology. Edinburgh: Churchill Livingstone, 1995:97-116.

4 Janne P, Carpenter Y, Willems G. Colonic mucosal atrophy induced by a liquid elemental diet in rats. $\mathrm{Am} \mathcal{F} \mathrm{Dig} \mathrm{Di}$ 1977;22:808-12.

5 Goodlad RA, Wright NA. The effects of addition of cellulose or kaolin to an elemental diet on intestinal cell proliferation in the mouse. Brf Nutr 1983;50:91-8.

6 Goodlad RA, Lenton W, Ghatei MA, et al. Effects of an elemental diet, inert bulk and different types of dietary fibre on the response of the intestinal epithelium to refeeding in the rat and relationship to plasma gastrin, refeeding in the rat and relationship to plasma gastrin,
enteroglucagon, and PYY concentrations. Gut 1987;28: enterogluca.
7 Goodlad RA, Ratcliffe B, Fordham JP, et al. Does dietary fibre stimulate intestinal epithelial cell proliferation in germ free rats? Gut 1989;30:820-5.

8 Wyatt GM, Horn N, Gee JM, et al. Intestinal microflora and gastrointestinal adaptation in the rat in response to non-digestible dietary polysaccharides. Br f Nutr 1988;60: 197-207.

9 Pell JD, Johnson IT, Goodlad RA. The effects of, and interactions between fermentable dietary fibre and lipid in germ free and conventional mice. Gastroenterology 1995;108: $1745-52$.

10 Goodlad RA, Ratcliffe B, Lee CY, et al. Dietary fibre and the gastrointestinal tract: differing trophic effects on muscle and mucosa of the stomach, small intestine and colon. Eur and mucosa of the stomach, small intestinc $1995 ; 49$ (suppl 3):S178-81.

11 Goodlad RA, Ratcliffe B, Lee CY, et al. Dietary fibre and the gastrointestinal epithelium: differential response in the stomach, small intestine and colon of conventional and germ-free rats. In: Waldron KW, Johnson IT, Fenwick GR, eds. Food and cancer prevention: chemical and biological aspects. Cambridge: Royal Society of Chemistry, 1993: 364-8.

12 Totafurno J, Bjerknes $M$, Cheng $H$. The crypt cycle. Crypt and villus production in the adult intestinal epithelium. Biophys f 1987;52:279-94.

13 Cheng $\mathrm{H}$, Bjerknes $\mathrm{M}$. Whole population cell kinetics and postnatal development of the mouse intestinal epithelium. Anat Rec 1985;211:420-6.

14 St Clair WH, Osborne JW. Crypt fission in the small intestine of the rat. Br f Cancer 1986;7:39-41.

15 Sullivan PB, Brueton MJ, Tabara Z, et al. Epidermal growth factor in necrotising enteritis. Lancet 1991;338:53-4.

16 Cairnie AB, Millen BH. Fission of crypts in the small intestine of the irradiated mouse. Cell Tissue Kinet 1975;8:18996.

17 Cheng H, McCulloch C, Bjerknes M. Effects of 30\% intestinal resection on whole population cell kinetics of mouse intestinal epithelium. Anat Rec 1986;215:35-41.

18 Levi S, Goodlad RA, Stamp G, et al. Effects of non-steroidal anti-inflammatory drugs and misoprostol on gastric and duodenal epithelial proliferation with arthritis. Gastroenterology 1992;102:1605-11.

19 Park HS, Goodlad RA, Ahnen D, et al. Effects of epidermal growth factor and dimethylhydrazine on crypt size, cell proliferation, and crypt fission in the rat colon. Cell proliferation and crypt fission are controlled independently. $\mathrm{Am}$ f Pathol 1997;151:843-52.

20 Gustafsson BE. Germ-free rearing of rats (general technique). Acta Pathol Microbiol Scand 1948;(suppl LXXIII): $1-130$.

21 Gustafsson BE. Lightweight stainless steel systems for rearing germ-free animals. Ann N Y Acad Sci 1959;78:1728.

22 Fuller R. Microbiological monitoring of gnotobiotic isolators. In: Coates ME, Gustafsson BE, eds. The germ free aninal in biomedical research. London: Laboratory Animals Ltd, 1984:111-16.

23 Carr KE, McCullough JS, Nunn S, et al. Neutron and X-ray effects on small intestine summarized by using a mathematical model or paradigm. Proc R Soc Lond 1991;243: 187-94.

24 Goodlad RA. Microdissection-based techniques for the determination of cell proliferation in gastrointestinal epithelium: application to animal and human studies. In: Celis JE, ed. Cell biology: a laboratory handbook. New York: Academic Press, 1994:205-17.

25 Cummings JH, Englyst HN. Gastrointestinal effects of food carbohydrate. Am f Clin Nutr 1995;61:938S-45S.

26 Englyst HN, Quigley ME, Hudson GJ. Definition and measurement of dietary fibre. Eur f Clin Nutr 1995; 9(suppl 3):S48-62.

27 Heaton KW. Concepts of dietary fibre. In: Southgate DAT, Waldron K, Johnson IT, Fenwick GR, eds. Dietary fibre: chemical and biological aspects. Cambridge: Royal Society of Chemistry, 1990:3-10.

28 Young GP, McIntyre A, Albert V, et al. Wheat bran suppresses potato starch-potentiated colorectal tumorigenesis at the aberrant crypt stage in a rat model. Gastroenterology 1996;110:508-14.

29 Sharma R, Schumacher U. Morphometric analysis of intestinal mucins under different dietary conditions and gut flora in rats. Dig Dis Sci 1995;40:2532-9.

30 Hoensch HP, Steinhardt HJ, Weiss G, et al. Effects of semisynthetic diets on xenobiotic metabolizing enzyme activity synthetic diets on xenobiotic metabolizing enzyme activity Gastroenterology 1984;86:1519-30.

31 Kamath PS, Hoepfner MT, Phillips SF. Short chain fatty acids stimulate motility of the canine ileum. Am F Physiol 1987;253:G427-33.

32 Brunsgaard G, Eggum BO. Cecal and colonic tissue structure and proliferation as influenced by adaptation period and indigestible polysaccharides. Comp Biochem Physiol A 1995;112:573-83.

33 Brunsgaard G, Eggum BO. Small-intestinal tissue structure and proliferation as influenced by adaptation period and ndigestible polysaccharides. Comp Biochem Physiol A 1995; 112:365-77.

34 Ghatei MA, Ratcliffe B, Bloom SR, et al. Fermentable dietary fibre, the intestinal microflora and plasma hormones. Clin Sci 1997;93:109-12.

35 Bergman EN. Energy contributions of volatile fatty acids from the gastrointestinal tract in various species. Physiol $\operatorname{Rev} 1$ 1990;70:567-90. 
36 Schneeman BO, Richter BD, Jacobs LR. Response to dietary wheat bran in the exocrine pancreas and intestine of dietary wheat bran in the exoc

37 Leitch GJ, Visvesvara GS, Wahlquist SP, et al. Dietary fiber and giardiasis: dietary fiber reduces rate of intestinal infection by Giardia lamblia in the gerbil. Am f Trop Med Hyg 1989;41:512-20

38 Whitehead RH, Young GP, Bhathal PS. Effects of short chain fatty acids on a new human colon carcinoma cell line (LIM1215). Gut 1986;27:1457-63.

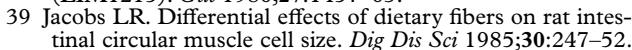

40 Stark A, Nyska A, Zuckerman A, et al. Changes in intestinal tunica muscularis following dietary fiber feeding in rats. A
morphometric study using image analysis. Dig Dis Sci 1995;40:960-6.

41 Park HS, Goodlad RA, Wright NA. Crypt fission in the small-intestine and colon-a mechanism for the emergence of g6pd locus-mutated crypts after treatment with mutagens. Am f Pathol 1995;147:1416-27.

42 Wasan H, Park HS, Liu KC, et al. APC in the regulation of intestinal crypt fission [abstract]. Gut 1997;40:A45. 